\title{
PRE-SERVICE SPORT SPECIALISTS’ PERCEPTIONS OF ACADEMIC INTEGRITY
}

\author{
Andra Fernate \\ Latvian Academy of Sport Education, Latvia \\ Baiba Smila \\ Latvian Academy of Sport Education, Latvia
}

\begin{abstract}
Academic integrity is fundamental value of pre-service sport specialists' professional competence developing, which promote public confidence in coaching and teaching as a process for professional and personal development. There is an ethical dissonance that the distribution of all dishonesty types was significantly higher than the perception of their legitimacy and that students conduct academic dishonesty despite its perception as unethical (Blau \& Eshet-Alkalai, 2017). The research aim is to reveal the pre-service sport specialists' perceptions of academic integrity and to find out the ways for promotion of academic integrity. The methods: a theoretical analysis of scientific literature, an interpretative phenomenological semi-structured interview, open and axial coding. The research sample 135 pre-service sport specialist, voluntary participants, $47 \%$ - female, $53 \%$ - male. The main research results: academic integrity perception is important for the development of pre-service sport specialists' professional competence. Pre-service sport specialists' main opinion about benefit of being academically dishonest is time saving and personal gain. The main causes of academic dishonesty are laziness, lack of knowledge and competence, searching for an easy way.
\end{abstract}

Keywords: academic integrity, pre-service sport specialists.

\section{Introduction}

Education and research are important values in modern society. Higher education is essential for the growth and development of the country's economy worldwide. Therefore, students, lecturers, higher education institutions and society as a whole are promoting academic integrity. It is very important to respond consistently to student plagiarism in any higher education institution, as the purpose of studies is to preserve the values of integrity and justice and to maintain academic integrity (Maio et al., 2019). Higher education institutions across Europe are responding in different ways to the challenge of plagiarism among students in the internet age (Glendinning, 2014).

Manifestations of academic dishonesty point to a lack of positive effort and indicate the need for penalties (Bieliauskaite, 2014). Studies show that plagiarism and academic dishonesty in higher education institutions in Europe is considered 
to be problematic. Research confirm that academic integrity policy and systems to ensure academic integrity are poorly defined in higher education institutions in many parts of Europe (Glendinning, 2014).

The most important task of education is to develop the integrity of an individual by providing knowledge that enables one to assess the conformity or discrepancy of a person's will and behaviour to values recognized in the society. Integrity is the human conscience that reflects social ethics (Bieliauskaite, 2014). Clear terminology of academic integrity has not been developed in Latvia (Upleja, 2012). The most important value of higher education institutions is academic integrity. A value-based approach to studies promotes the development of professional values of pre-service professionals, if it is provided by education processes and transparency (Bieliauskaite, 2014). Lithuanian universities communicate the message on academic integrity from an educative perspective, but the Latvian universities follow principally a punitive approach (AnohinaNaumeca et al., 2018).

The major obstacles to the progress of academic integrity across the European Union are the lack of consensus on what causes plagiarism, differing academic standards, expectations of the teaching staff and educational priorities (Glendinning, 2014), as well as the shift of existing research towards student academic dishonesty rather than administrative aspects (Brown, 2015). Despite the research already performed on academic integrity issues, plagiarism among students still remains a concern, and further research is needed in this area. Only when we have a deeper understanding of a person who responds to academically dishonest behaviour can we know better how to consistently and effectively address student plagiarism (Maio et al., 2019).

That is why the research aim of this study is to reveal the pre-service sport specialists' perceptions of academic integrity and to find out the ways for promotion of academic integrity. In order to achieve the said aim, the following research methods will be used: a theoretical - analysis of scientific literature, an interpretative phenomenological semi-structured interview, open and axial coding.

\section{Theoretical Framework}

This subchapter will discuss the understanding of the essence of "academic integrity" and "perception of academic integrity" and its characteristic indicators.

Academic integrity is academic honesty (Macfarlane et al., 2014). The meaning of the term is very broad, including the ethical use of information and resources (Anohina-Naumeca et al., 2018), while recognizing the original source of information (Blau \& Eshet-Alkalai, 2017). The International Center for Academic Integrity defines academic integrity as a commitment to five 
fundamental values: honesty, trust, fairness, respect, and responsibility (Fishman, 2014). It embodies originality and creativity which underlies the academic culture (Adyasha \& Duraipandian, 2016). Students, on the one hand, have very different views on the concept of academic integrity: honesty is synonymous with responsibility, the need for knowledge and learning, honesty is a moral category, a model of intellectual behaviour (Langa, 2013).

But on the other hand, there is also academic dishonesty as part of academically unethical behaviour: cheating, plagiarism, falsifying data or information, copying without reference to the original source, submitting work done by others, submitting something someone else has said, others' ideas or other original work material without reference to the original source, bribery, extortion, fraudulent agreements, impersonation, political interference, nepotism, favouritism, racketeering magazines and conferences (Bretag et al., 2019; Bachore, 2016; Glendinning, 2014; Correa, 2011). The main reasons why students cheat are lack of leadership support from institutions, inadequate remuneration for teaching staff, sympathy and laziness of teaching staff, difficulties in detecting and proving cheating, weak academic dishonesty prevention policy, procedures, sanctions, lack of support for disclosure and collection of evidence, non-detection of academic misdemeanours, teaching staff have not set a good example (Bretag et al., 2019; Bachore, 2016; Macfarlane et al., 2014, Correa, 2011; Wilkinson, 2009; Roberts, 2007; Miller et al., 2007). The use of technology per se does not significantly affect academic dishonesty (Blau \& Eshet-Alkalai, 2017). Moreover, agreements on cheating are concluded because of dissatisfaction with the teaching and learning environment, the belief that there are "many opportunities to cheat" and speaking a language other than English at home (Bretag et al., 2019). Reasons related to asking for contract work were divided into five categories, which include: academic abilities, perseverance, personal problems, competing goals and self-discipline (Amigud \& Lancaster, 2019). In a study conducted in Latvia in 2014, students mentioned three choices from the offered list of reasons for plagiarism: "They think they won't get caught", "It's easy to copy and paste from the internet" and "They don't want to learn anything but just pass the task" (Stabingis et al., 2014).

Most research concludes that students with lower abilities are more likely to admit to being involved in cheating, but there are findings that show that students with higher abilities also cheat (Miller et al., 2007). Almost 40 percent of all students occasionally give their notes to their friends to help with preparing their written tasks for assessment, and about 30 percent of students occasionally help their friends with writing their assignments for assessment, while 20 percent borrow friends' notes which they used to prepare their own assessment assignments. Almost a quarter of students reveal that they have worked together with others to complete assessment tasks that were supposed to be done 
individually. Overall, the majority (80 percent) of all students felt that these collegial acts were not dishonesty or plagiarism (Roberts, 2007). Studies show that lecturers and students have a general lack of understanding of plagiarism and a wide range of values and attitudes on this issue (Pickard, 2006).

In many cases, existing academic integrity education programmes lack comprehensive information on values, potential integrity risks and shortcomings in assessment, as study programmes mainly focus on plagiarism, student responsibilities and references (Sefcik et al., 2020). In order to reduce cheating through the use of outsourcing agreements, it is necessary to support the development of such a teaching and learning environment that promotes strong interaction between students and teaching staff and an appropriate evaluation structure (Bretag et al., 2019).

The findings of the research clearly show that the academic integrity policy of the largest Latvian and Lithuanian public universities cannot fully satisfy the components of an exemplary academic integrity policy (Anohina-Naumeca et al., 2018). In order to implement changes in education institution policy, research is necessary to determine staff and student attitudes towards plagiarism and to develop a joint system, gathering evidence, raising awareness of these issues and raising a discussion on related pedagogical issues (Pikard, 2006). Such an approach could facilitate changes in the culture of an education institution. Therefore, this research is an opportunity to gain evidence by exploring the understanding of academic integrity of students in a higher education institution in order to promote the selection of optimal ways to promote academic integrity.

\section{Methodology}

In order to determine the pre-service sport specialists' perceptions of academic integrity and to find out the ways for promotion of academic integrity was used a theoretical analysis of scientific literature, an interpretative phenomenological semi-structured interview and open and axial coding. Research participants - 135 pre-service sport specialists (students), voluntary participants, $47 \%$ - female, 53\% - male. Information was collected from Bachelor students. By using an interpretative phenomenological semi-structured e-interview (Smith et al., 2009), the pre-service sport specialists' perceptions of academic integrity were determined. The interpretative phenomenological semi-structured einterview was conducted from the beginning of March 2019 until the end of November. The e-interview items were based on the following themes:

- understanding and awareness of academic integrity (Macfarlane, et al., 2014; Bieliauskaitè, 2014; Fishman, 2014; Glendinning, 2014; Langa, 2013); 
- $\quad$ understanding of plagiarism and self-plagiarism (Amigud \& Lancaster, 2019; Bretag et al., 2019; Bachore, 2016; Correa, 2011; Roberts, 2007; Miller et al., 2007);

- $\quad$ educators' role in promoting academic integrity (Sefcik et al., 2020; Bretag et al., 2019; Pikard, 2006).

Qualitative data processing - coding (open and axial (Strauss \& Corbin, 1998)) and interpretation - was carried out with MAXQDA2020 programme. Statements about understanding of academic integrity of students in a higher education institution were coded in relation with the values, behaviour and conduct of students in all aspects of their practice (Macfarlane et al., 2014). Axial coding was carried out with the aim to construct linkages between data.

\section{Research results}

When responding to a question about what academic integrity (honesty) is in their opinion, students mostly describe it as an action (Fig. 1). Students believe that it is non-violation of moral norms (39.7\%). Honesty manifests itself in behaviours, for example, "ability to do the job honestly", "if the student and the educator are honest with each other and fulfil the given requirements on time", "as well as honest assessment", "use of references to materials used in their work", "not falsifying data for implementation of research results", "provision of true information on the research conducted, using well-established research methods", "appropriate conduct in accordance with the norms and rules of conducting particular work". However, $12.9 \%$ of students believe that academic integrity is one's own work, for instance, "when one's own work is done independently, without the mediation of others", "one does their own independent works assigned in study courses, homework, reports, term papers, etc.", "self-designed research work for which the student is given assessment", " when the student analyses and studies materials on his/her own”. Meanwhile $21.6 \%$ of students said that they did not have an opinion on this issue. 
Fernate \&Smila, 2020. Pre-Service Sport Specialists’ Perceptions of Academic Integrity

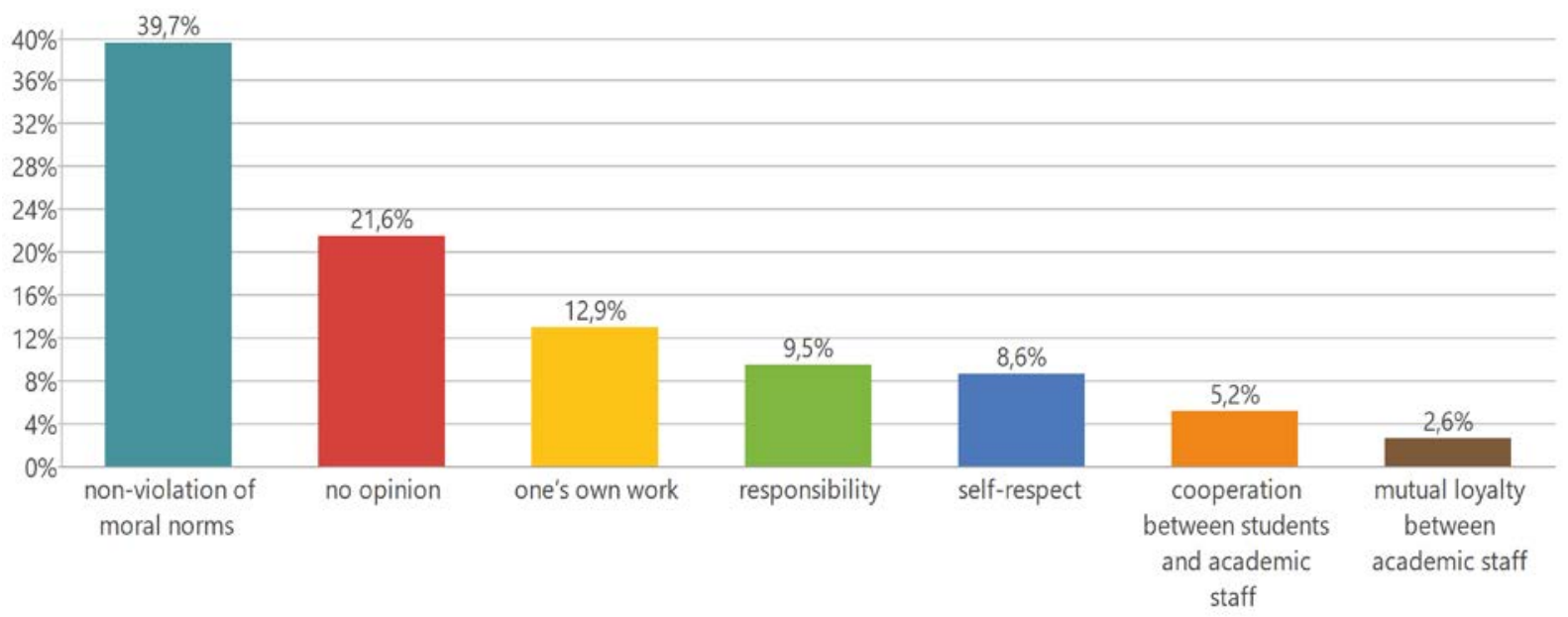

Figure 1 Students' Understanding of Academic Integrity (n=135)

However, 9.5\% of students believe that academic integrity is responsibility, for example, "being responsible towards the work to be done", "being responsible for one's own studies - not submitting work done by others", "being able to accept one's own mistakes and answer questions in the best of one's conscience, whatever the answer may be", "not to plagiarize and be responsible for one's own work". Furthermore, $8.6 \%$ of students think that academic integrity is self-respect because it is "respect for oneself first", "not lying to yourself”, "respect for one's own work”, "being honest with oneself”, “acting honestly towards oneself”.

Cooperation between students and academic staff is seen as an expression of academic integrity by $5.2 \%$ of respondents, for example, "it is the cooperation between students and lecturers in both studies and research to ensure the study process, its quality and compliance with general and internal norms, as well as compliance with guidelines of developing an academic paper, etc.” Furthermore, $2.6 \%$ of students see academic integrity in the mutual loyalty between academic staff. Through axial coding, a linkage was determined between beliefs about nonviolation of morally ethical norms and cooperation between students and lecturers and self-conducted work, as well as a linkage between the mutual loyalty between lecturers and self-respect.

When responding to a question about what they think plagiarism is (Fig. 2), students mention that it is dishonest conduct because it is theft of foreign information without reference to the source (55.5\%), for instance, "using the thoughts of others without their consent", "selfishly using the work of another author, claiming it as one's own”, “copying a work”, “appropriation of someone's work and its presentation as one's own", "plagiarism is the direct use of information (articles, research, papers) in one's own work without using references in the mentioned text", "stealing someone's answer word by word for one's own needs”, “stolen work without investing virtually no time of one's own 
in the creation/execution of the work", "material one presents as their own but which in fact belongs to someone else", "plagiarism is someone’s work used in one's own work without indicating the name of the author of the original work", "using another author's opinion or results as one's own without references", "using some or all of another person's work with similar content, naming it as one’s own”.

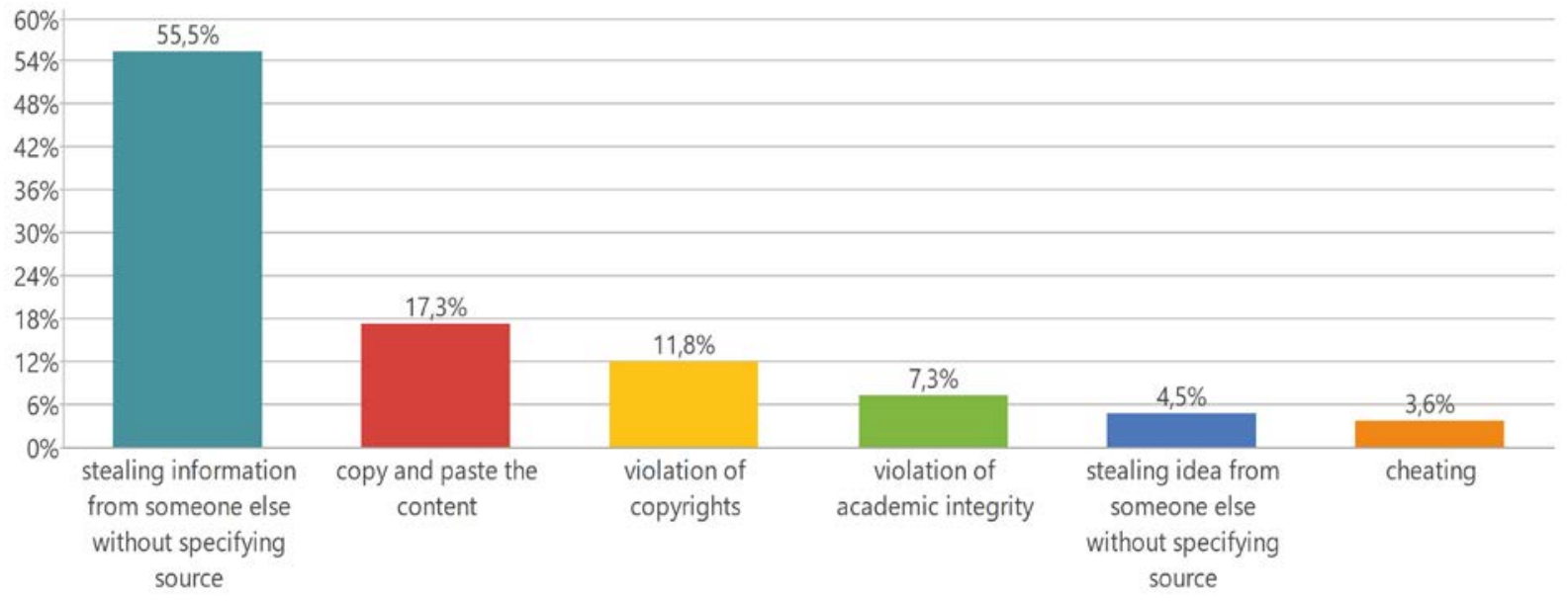

Figure 2 Students' Understanding of Plagiarism (n=135)

Students also consider plagiarism to be the act of copy-pasting the content (17.3\%), for example, "copying the work of others", "when some information is copied", "information copied from someone else's work into one's own work without reference to author's opinion”, “copying someone else's work and submitting it as one's own”, "creating a paper by copying someone else's work", "identical papers", "copied, not self-developed", "plagiarism is work identical to that of another student", "copied work or copied information from the internet". Furthermore, $11.8 \%$ of pre-service sport specialists believe that plagiarism is a violation of copyrights, for instance, "counterfeiting, not one's own work", "personalization of someone else's work", "work done by another person which someone else assumes as their own", "work which one has not done by themselves but claims that it is theirs", "information used without reference to the author" "works used without copyright permission". However, $7.3 \%$ of students consider plagiarism to be a violation of academic integrity because "academic honesty has been violated", "severe academic violation", "violation of rights", "unfair fulfilment of work", "work done unfairly". Next, $4.5 \%$ of pre-service sport specialists describe plagiarism as stealing someone else's ideas without reference to the source: "a person's idea is taken without reference", "it is someone else's idea", "it is theft of ideas", "when a person steals another person's idea". Still, $3.6 \%$ of students think that plagiarism is cheating: "misleading work" or "work written off of someone else". 
When responding to a question about what they think self-plagiarism means (Fig. 3), students believed that it is dishonest behaviour. Respondents mostly consider self-plagiarism to be reusing any amount of one's own information or work (50\%), for example, "multiple use of the same information”, "when one's own already developed work is used in another work that is not developed yet without reference to this work", "use of one’s own works in future works", "when one uses their own work in several projects, they are not creating a new work but several copies", "submitting the same paper in different study courses", "when the same information is taken from one's previous work for their next work". Furthermore, $17.3 \%$ of students consider self-plagiarism to be theft of one's own thoughts, for example, "when you give your work to others", "stealing of one's own thoughts", "when you copy from yourself”, "slightly modified paper", "sale of one’s own paper”.

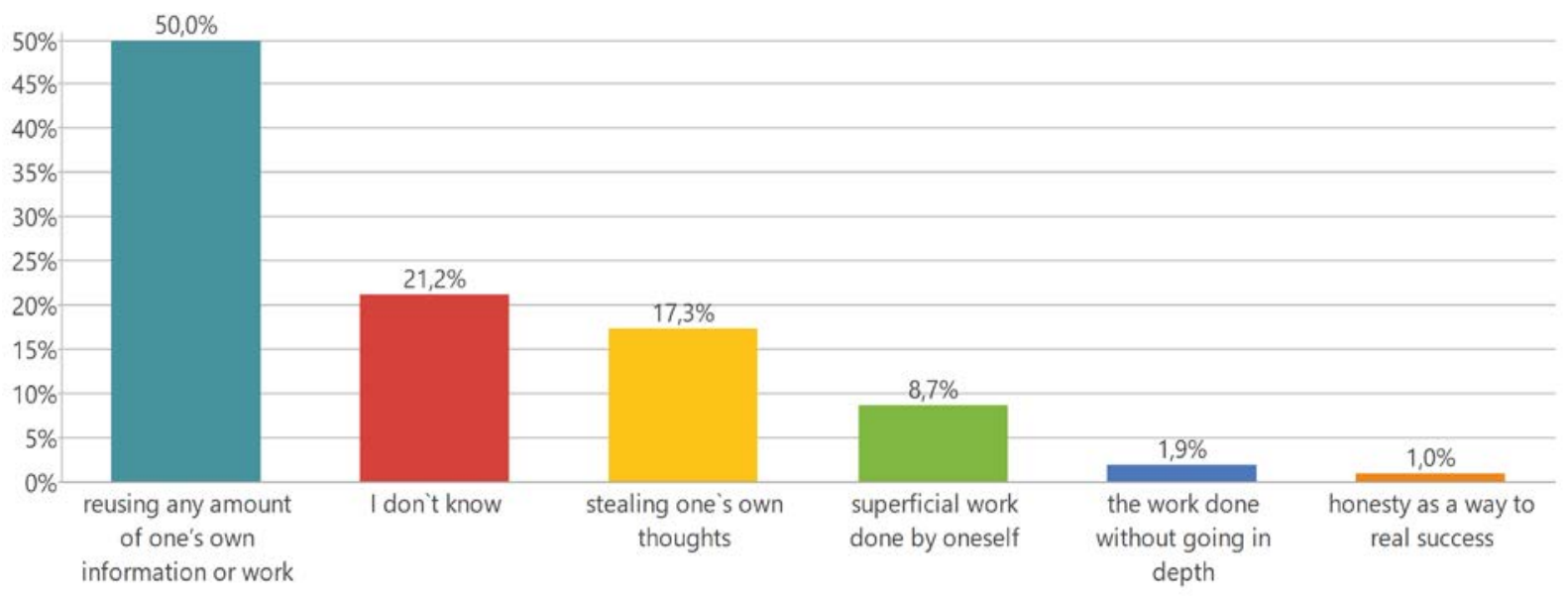

Figure 3 Students' Understanding of Self-Plagiarism (n=135)

However, 21.2\% of students do not know what self-plagiarism is. Students describe self-plagiarism as plagiarism because they think that self-plagiarism is superficial work done by oneself (8.7\%), for example, "the author of the papers does not use references", "mixing up information”, "when I copy someone", "internet-based information which has been submitted as one's own thoughts and insights”. Self-plagiarism is a work done without fully understanding its essence, at least $1.9 \%$ of respondents believe so, while $1 \%$ believe that it is an honest way to real success.

When describing the causes of academic dishonesty, students most often mention laziness (25\%), lack of time (21.9\%), lack of knowledge and competence (13.8\%), searching for the easiest way (10\%) and gaining personal benefit (7.5\%). Causes of academic dishonesty also include frivolous attitude (4.4\%), lack of conscience (4.4\%), personal ambitions (3.1\%), indifference from academic staff (2.5\%) and lack of creativity (1.9\%). Those students who consider lack of 
knowledge and competence to be the cause of academic dishonesty also cite lack of time. In turn, students who think that plagiarism is theft of someone else's information without references also mention gaining personal benefit as a reason for dishonest behaviour.

When describing the role of lecturers in academic dishonesty, students believe that lecturers should be responsible for academic integrity (19.6\%), control information (14.3\%), explain how to refer to someone else's thoughts (8.9\%), carefully look into students' works (5.4\%), know the most popular sources of reference (1.8\%), punish (3.6\%) and motivate students to be themselves (0.9\%). Academic dishonesty is facilitated by biased assessment (8\%), indifference $(8 \%)$ and personal gain (1,8\%). Furthermore, $9.8 \%$ of students believe that lecturers cannot influence academic dishonesty, while $8.9 \%$ believe that they can and another $8.9 \%$ think that lecturers play a very important role.

\section{Discussion}

As with other studies on academic integrity (Macfarlane et al., 2014; Bieliauskaite, 2014; Fishman, 2014; Glendinning, 2014; Langa, 2013), preservice sport specialists who are currently studying also believe that academic integrity is honesty, which is manifested through non-violation of morally ethical norms, independent study work, responsibility, self-respect, cooperation between students and lecturers and mutual loyalty between lecturers. The conducted studies prove that students have a general lack of understanding of plagiarism and a wide range of values and attitudes on this issue (Pickard, 2006), and also in this study $21.2 \%$ of students do not know what self-plagiarism is, while $11.6 \%$ do not understand its essence.

People are willing to sacrifice their long-term well-being in favour of gaining benefits short-term, which also explains such behaviours as drug use, unsafe sex and risky driving. This may also apply to violations of academic integrity (Rettinger, 2007). In this study too, 7.5\% of students see personal gain as a reason for academically dishonest behaviour. The main reasons found in this study are laziness, lack of time, lack of knowledge and competence, looking for an easy way and personal gain, but other studies found that reasons (Macfarlane at el, 2014; etc.) why students cheat are sympathy and laziness of teaching staff, weak academic dishonesty prevention policy, procedures, sanctions, teaching staff have not set a good example.

In order to help students understand the essence of academic integrity and to act academically honestly, students need help with internalizing the value of academic integrity through education, disciplinary measures, socially empowering corresponding behaviour, providing positive role models and ensuring a positive academic environment. 
Fernate \&Smila, 2020. Pre-Service Sport Specialists’ Perceptions of Academic Integrity

\section{Conclusions}

Currently studying pre-service sport specialists consider academic integrity to be honesty, which is manifested through non-violation of morally ethical norms, independent study work, responsibility, self-respect, cooperation between students and lecturers and mutual loyalty between lecturers.

Students understand plagiarism as stealing foreign information without reference to the source, copying content, copyright infringement, violation of academic integrity, stealing someone else's ideas without reference to the source and cheating. Self-plagiarism is described as a repeated use of one's own information or work on theft of one's own thoughts. 21.2\% of students do not know what self-plagiarism is, while $11.6 \%$ do not understand its essence.

The main causes of academic dishonesty most often are laziness (25\%), lack of time (21.9\%), lack of knowledge and competence (13.8\%), searching for an easy way (10\%) and personal gain (7.5\%). Students believe that lecturers play a very important role and can influence academic dishonesty. The lecturer should be responsible for academic integrity (19.6\%), control the information (14.3\%), explain how to reference someone else's thoughts (8.9\%). In order to promote academic integrity, an appropriate academic culture should be developed within a higher education institution, fostering the internalization of the values of academic integrity in students.

\section{References}

Adyasha, R., \& Duraipandian, R. (2016). Relationship between Creativity and Academic Integrity of Students: An Empirical Study of Management Students in India. Management Studies and Economic Systems, 2(4), 255-262. Retrieved from http://www.msaes.org/ article_40557.html

Amigud, A., \& Lancaster, T. (2019). 246 Reasons to Cheat: An Analysis of Students’ Reasons for Seeking to Outsource Academic Work. Computers \& Education. 134, 98-107. DOI:10.1016/j.compedu.2019.01.017

Anohina-Naumeca, A., Tauginienè, L., \& Odineca, T. (2018). Academic Integrity Policies of Baltic State-Financed Universities in Online Public Spaces. International Journal for Educational Integrity, 14(8), 1-14. DOI:10.1007/s40979-018-0031-z

Bachore, M. (2016). The nature causes and practices of academic dishonesty/cheating in higher education: The case of Hawassa University. Journal of Education and Practice, 7(19), 14-20. Retrieved from https://files.eric.ed.gov/fulltext/EJ1109249.pdf

Bieliauskaite, J. (2014). On the Way to Professionalism - The Promotion of Law Students' Academic Integrity. Procedia - Social and Behavioral Sciences, 116, 4229-4234. DOI: https://doi.org/10.1016/j.sbspro.2014.01.922

Blau, I., \& Eshet-Alkalai, Y. (2017). The ethical dissonance in digital and non-digital learning environments: Does technology promotes cheating among middle school students? Computers in Human Behavior. 73, 629-637. DOI: https://doi.org/10.1016/ j.chb.2017.03.074 
SOCIETY. INTEGRATION. EDUCATION

Proceedings of the International Scientific Conference. Volume VI, May $22^{\text {th }}-23^{\text {th }}, 2020.206-216$

Bretag, T., Harper, R., Burton, M., Ellis, C., Newton, Ph., Rozenberg, P., Saddiqui S., \& van Haeringen, K. (2019). Contract cheating: a survey of Australian university students. Studies in Higher Education. 44(11), 1837-1856. DOI: https://doi.org/10.1080/ 03075079.2018.1462788

Brown, S.R. (2015). Academic integrity practices by faculty in physical therapy education programs. Physiotherapy, 101, e182 - e183. DOI: https://doi.org/10.1016/ j.physio.2015.03.340

Fishman, T. (Ed.) (2014). The fundamental values of academic integrity. 2nd edition. Clemson University: International Center for Academic Integrity. Retrieved from https://academicintegrity.org/wp-content/uploads/2017/12/Fundamental-Values2014.pdf

Glendinning, I. (2014). Responses to student plagiarism in higher education across Europe. International Journal for Educational Integrity, 2(2), 4-20. DOI:10.21913/IJEI.v1 $0 \mathrm{i} 1.930$

Langa, C. (2013). Investigation of Students' Attitude to Academic Honesty-Empirical Study. Procedia - Social and Behavioral Sciences, 76, 426-430. DOI: https://doi.org/ 10.1016/j.sbspro.2013.04.140

Macfarlane, B., Zhang, J., \& Pun, A. (2014). Academic Integrity: A Review of the Literature. Studies in Higher Education, 39(2), 339-358, DOI: 10.1080/03075079.2012.709495

Maio, C.D., Dixon, K., \& Yeo, S. (2019). Academic staff responses to student plagiarism in universities: A literature review from 1990 to 2019. Issues in Educational Research, 29(4), 1131-1142. Retrieved from http://www.iier.org.au/iier29/demaio.pdf

Miller, A.D., Murdock, T.B., Anderman, E.M., \& Poindexter, A.L. (2007). Who are All These Cheaters? Characteristics of Academically Dishonest Students. In Anderman E. M., Murdock T.B. (Ed.), Psychology of Academic Cheating (pp. 9-32). Academic Press, DOI: https://doi.org/10.1016/B978-012372541-7/50003-6

Pickard, J. (2006). Staff and student attitudes to plagiarism at University College Northampton. Assessment \& Evaluation in Higher Education, 31(2), 215-232, DOI: 10.1080/ 02602930500262528

Rettinger, D. (2007). Applying decision theory to academic integrity decisions. In E. Anderman \& T. Murdock (Eds.), Psychology of academic cheating (pp. 141-167). San Diego, CA: Elsevier

Roberts, T.S. (2007). Student Plagiarism in an Online World: Problems and Solutions. 40-41. Hershey, PA: IGI Global. DOI:10.4018/978-1-59904-801-7

Sefcik, L., Striepe, M., \& Yorke, J. (2020). Mapping the landscape of academic integrity education programs: what approaches are effective? Assessment \& Evaluation in Higher Education, 45(1), 30-43. DOI: https://doi.org/10.1080/02602938.2019.1604942

Smith, J.A, Flowers, P., \& Larkin, M. (2009). Interpretative Phenomenological Analysis: theory, method and research. London: SAGE.

Stabingis, L., Glendinning, I., Šarlauskienè, L., \& Čepaitienè, N. (2014). Plagiarism Policies in Latvia, IPPHEAE project report. Retrieved from http://www.plagiarism.cz/ippheae/

Upleja, A. (2012). Akadēmiskais godīgums un izpratne par to [Academic integrity and its understanding]. Retrieved from https://lbbjss.wordpress.com/2012/04/27/akademiskaisgodigums/

Wilkinson, J. (2009). Staff and Student Perceptions of Plagiarism and Cheating. International Journal of Teaching and Learning in Higher Education, 20(2), 98-105. Retrieved from http://www.isetl.org/ijtlhe/ 